commended, however, in the generation of hypotheses. The two cases presented here may point to a genetic link in the development of gut lymphoma in support of previous reports. ${ }^{12}$ On the other hand, the EB virus titres were surprisingly high, and one patient had a history of malaria. The association of EB virus, malaria, and Burkitt's lymphoma is well known, ${ }^{4}$ and studies of non-Burkitt's lymphoma have yielded complexes of low molecular weight RNA and reverse transcriptase. "Further study of intestinal lymphoma may yield more clues about the cause of this group of diseases.

We thank Mr A J Mack and Dr W G S Spilg for advice and encouragement, Dr J C Campbell for histological reporting, Professor J R Anderson for immunoperoxidase investigations, Professor M A Ferguson-Smith for the chromosomal analyses, and Dr R G Sommerville for virological screening.

${ }^{1}$ Maurer, H, et al, Cancer, 1976, 37, 2224.

2 Hambleton, G, Proceedings of the Royal Society of Medicine, 1969, 62, 1093.

3 Smith, P G, and Pike, M C, Cancer Research, 1976, 36, 660.

${ }^{4}$ Epstein, M A, Achong, B G, and Barr, Y M, Lancet, 1964, 1, 802.

${ }^{5}$ Spiegelman, S, et al, Cancer Research, 1973, 33, 1515.

(Accepted 27 September 1977)

Victoria Infirmary, Glasgow G42 9TY

E FREEDLANDER, BSC, $M B$, registrar in surgery

L H KISSEN, MB, CHB, senior registrar in pathology

Department of Clinical Oncology, University of Glasgow, Glasgow G12 9LY

J G MCVIE, MB, MRCP, senior lecturer in clinical oncology

\section{Arthritis simulating thrombosis on urokinase scan}

${ }^{99} \mathrm{~m}$ Tc-labelled urokinase is used to diagnose thrombosis in leg veins because, unlike ${ }^{125}$ I-labelled fibrinogen, it detects clot that has already formed and can disclose thrombi in the thigh as well as the calf. . $^{1-3}$ Despite these advantages the specificity of the technique is not known. We report two cases where arthritis of the knees caused a falsepositive diagnosis of venous thrombosis.

\section{Case reports}

A 56-year-old woman with an eight-year history of rheumatoid arthritis presented with clinical and electrocardiographic evidence of myocardial infarction. Both knees were warm and painful, and small effusions were detectable. In the calves there was no tenderness, swelling, or superficial venous distension. The RA latex test result was positive. Although scanning with ${ }^{99} \mathrm{~m}$ Tc-labelled urokinase disclosed increased radioactivity over both knees (see figure) bilateral venograms performed the next day showed normal results.

A 60 -year-old woman with a six-year history of seropositive rheumatoid arthritis was admitted to hospital for investigation of anaemia. Both knees showed radiological features of rheumatoid arthritis-that is, narrowed joint spaces and marginal lipping-but the patient did not complain of pains in her joints. The legs were wasted, without any features of venous thrombosis. Scanning with ${ }^{99} \mathrm{mT}$ c-labelled urokinase showed increased activity over both knees (figure) although bilateral venograms performed two hours later were normal.

\section{Comment}

The classic clinical features of deep venous thrombosis in the legs are only infrequently present, and various techniques-for instance, venography, isotope scanning, doppler ultrasound, and plethysmography-have been used to detect thrombi that are not clinically apparent. The results of using the plasminogen activator urokinase have proved promising. Necropsy studies in dogs have shown that $99 \mathrm{mT}^{\mathrm{T}}$-labelled urokinase localises in blood clots ${ }^{4}$ and in man there is a good correlation between thrombi detected by venography and thrombosis detected by ${ }^{99 \mathrm{~m} T c}$-labelled urokinase.

These two cases indicate that rheumatoid arthritis can masquerade as venous thrombosis when this method of detection is used. Furthermore, the second case illustrates that this may occur in the absence of pain or discomfort in the affected joints. These observations call into question whether other causes of hyperaemia-for example, cellulitis-cause false-positive diagnoses, and also emphasise that
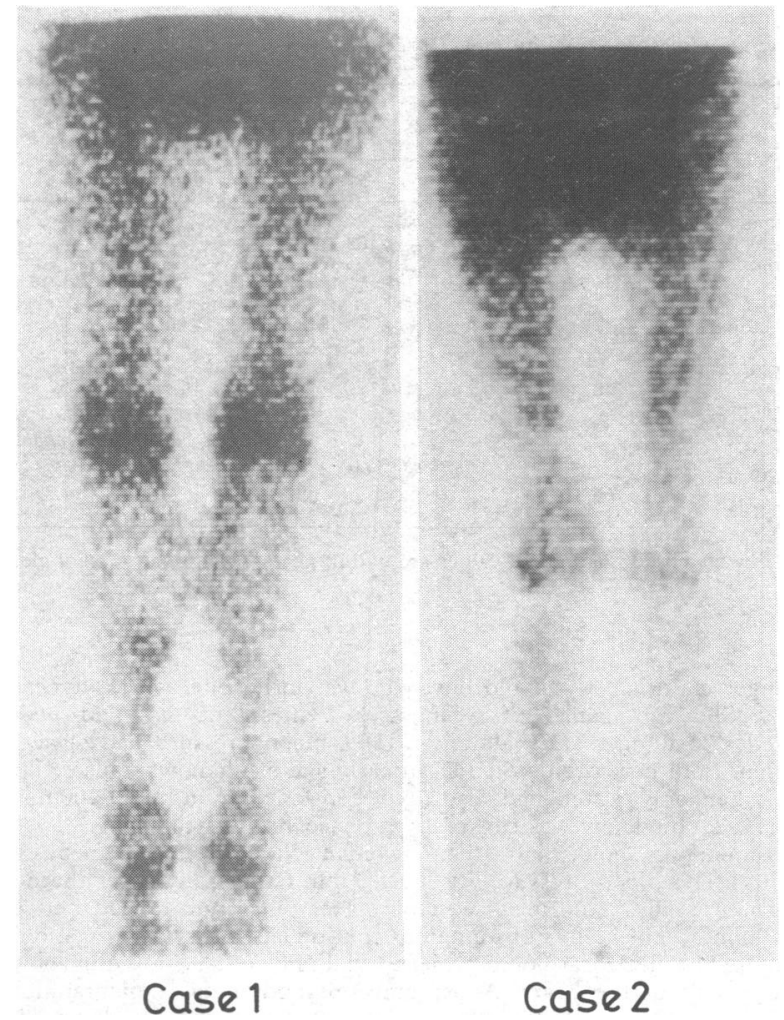

${ }^{99} \mathrm{~m}$ Tc-labelled urokinase scans showing increased activity over both knees in cases 1 and 2 .

evidence of arthritis should be sought before anticoagulant treatment is instigated on the basis of increased activity on a urokinase scan.

${ }^{1}$ Flanc, C, Kakkar, V V, and Clarke, M B, British fournal of Surgery, 1968, $\mathbf{5 5}, 742$.

2 Negus, D, et al, British fournal of Surgery, 1968, 55, 835.

3 Miller, W T, and Smith, J F B, Lancet, 1974, 2, 695.

4 Alkjaersig, N, Fletcher, A P, and Sherry, S, fournal of Clinical Investigation, 1959, 38, 1086.

(Accepted 20 September 1977)

Departments of Cardiology, Medical Physics, and Radiology, Ninewells Hospital, Dundee DD2 1UB

G P McNEILL, PHD, MRCP, lecturer

F HUTCHINSON, PHD, medical physicist

N C TAYLOR, DCH, MRCP, registrar

M D CLEE, MRCP, senior house officer (present appointment: registrar in medicine)

J W SHAW, DMRD, FFR, consultant radiologist

\section{Normotensive familial phaeochromocytoma with predominant noradrenaline secretion}

Hypertension is a typical symptom of phaeochromocytoma. We report a patient with familial phaeochromocytoma who was normotensive despite a persistently raised urinary noradrenaline excretion.

\section{Case report}

A 40-year-old woman was referred to our hospital because of suspected phaeochromocytomas. A phaeochromocytoma had been discovered in her 